\title{
Mycotic aneurysm caused by Graphium species in a dog
}

\author{
Yousuke MURATA ${ }^{1)}$, James Kenn CHAMBERS ${ }^{1)}$, Kazuyuki UCHIDA ${ }^{1) *}$, Ko NAKASHIMA ${ }^{2)}$, Yasuko HANAFUSA ${ }^{3)}$, \\ Mitsutaka IKEZAWA $^{4)}$, Takashi SUGITA ${ }^{5)}$ and Hiroyuki NAKAYAMA ${ }^{1)}$ \\ 1) Department of Veterinary Pathology, Graduate School of Agricultural and Life Sciences, The University of Tokyo, 1-1-1 Yayoi, Bunkyo- \\ ku, Tokyo 113-8657, Japan \\ 2) Japan Small Animal Medical Center, 2-27-4 Nakatomiminami, Tokorozawa, Saitama 359-0003, Japan \\ 3) Bacterial and Parasitic Disease Research Division, National Institute of Animal Health, National Agriculture and Food Research \\ Organization, 3-1-5 Kannondai, Tsukuba, Ibaraki 305-0856, Japan \\ 4) Pathology and Pathophysiology Research Division, National Institute of Animal Health, National Agriculture and Food Research \\ Organization, 3-1-5 Kannondai, Tsukuba, Ibaraki 305-0856, Japan \\ ${ }^{5)}$ Department of Microbiology, Meiji Pharmaceutical University, 2-522-1 Noshio, Kiyose, Tokyo 204-8588, Japan
}

(Received 23 February 2015/Accepted 21 April 2015/Published online in J-STAGE 3 May 2015)

ABSTRACT. A 10-year-old castrated male mixed-breed dog exhibited vomiting, lethargy and anorexia. An abdominal ultrasound examination revealed a focal dilation of the abdominal aorta. The dog died 2 days after examination, and necropsy revealed a ruptured aneurysm at the abdominal aorta between the kidneys. Histological examination revealed severe granulomatous and necrotizing pan-arteritis with fungal organisms. Graphium species was identified through DNA sequence analysis of the PCR product from formalin-fixed paraffin-embedded samples. To our knowledge, this is the first report of aortic aneurysm caused by Graphium species in a dog.

KEY WORDS: abdominal aorta, canine, Graphium species, mycotic aneurysm

doi: 10.1292/jvms.15-0105; J. Vet. Med. Sci. 77(10): 1285-1288, 2015

Aneurysm is a localized dilation of the vessels or heart, and occurs in usually large-sized elastic arteries. Aortic aneurysm results from high blood pressure and a weakening of the vessel wall caused by atherosclerosis, cystic medial degeneration, trauma, infection or arterial dissection [7, 13]. Abdominal aortic aneurysm may cause sudden death due to an aortic rupture. However, aortic aneurysm caused by a fungal infection is rare in humans and animals. The present report describes a canine case of mycotic aneurysm caused by Graphium species in the abdominal aorta.

A 10-year-old castrated male mixed-breed dog was presented to the Japan Small Animal Medical Center with a 1-week history of vomiting, lethargy and anorexia. An abdominal ultrasound examination revealed a focal dilation of the abdominal aorta $(5.0 \mathrm{~cm}$ in diameter and $7 \mathrm{~cm}$ in length). The dilation involved both renal arteries and cranial mesenteric arteries. The left side of the dilated vascular wall was severely thickened. Thoracic radiography and echocardiography as well as physical examination did not reveal any other abnormalities. The dog died two days after examination.

At necropsy, a large amount of hemorrhagic ascites and a ruptured aneurysm were observed in the peritoneal cavity

*Correspondence to: Uchida, K., Department of Veterinary Pathology, Graduate School of Agricultural and Life Sciences, the University of Tokyo, 1-1-1 Yayoi, Bunkyo-ku, Tokyo 113-8657, Japan. e-mail: auchidak@mail.ecc.u-tokyo.ac.jp

(C)2015 The Japanese Society of Veterinary Science

This is an open-access article distributed under the terms of the Creative Commons Attribution Non-Commercial No Derivatives (by-nc-nd) License $<$ http://creativecommons.org/licenses/by-nc-nd/3.0/>.
(Fig. 1). The wall of the aneurysm was unevenly thickened with hemorrhagic areas (Fig. 2). Other visceral organs were normal at gross examination. Tissues from the heart, lung, stomach, intestines, liver, pancreas, spleen, kidneys and adrenal glands were fixed in 10\% neutral-buffered formalin, routinely embedded in paraffin and then sectioned at $4 \mu \mathrm{m}$. Sections were stained with hematoxylin and eosin (HE), Masson's trichrome, periodic acid-Schiff (PAS), elastica van Gieson (EVG) and Gomori-Grocott methenamine silver (GMS). Examination for HE-stained sections revealed severe granulomatous and necrotizing pan-arteritis with fungal organisms. The vascular wall was necrotized, and hemorrhage was observed (Fig. 3). Inflammatory cells, mainly macrophages and lymphocytes, infiltrated in the tunica media and the tunica externa severely (Figs. 4 and 5a). The vascular endothelium was detached (Fig. 5b), and fibrosis was observed in the tunica media (Fig. 5c). Fungal infection was confined to the tunica intima of the aneurysm (Fig. 6a), and fungi were not observed in the tunica adventitia or any other organs examined. Ruptured elastic fibers accompanied by collagenous fibroplasia were observed on EVG-stained sections. The fungal organisms were positively stained both on PAS and GMS sections (Figs. 6b and 7). The organisms showed septate hyphae with slightly uneven widths (2-4 $\mu \mathrm{m})$, irregularly branching and thin walled with focal bulbous dilation.

Immunohistochemistry (IHC) was performed for selected sections using a universal immunoenzyme polymer method, the Histofine Simple Stain MAX-PO kit (Nichirei Co., Tokyo, Japan). Mouse monoclonal antibodies against Aspergillus spp. (clone WF-AF-1; 1:2048, Dako, Carpinteria, CA, U.S.A.) and Rhizomucor spp. (clone WSSA-RA-1; 1:256, 


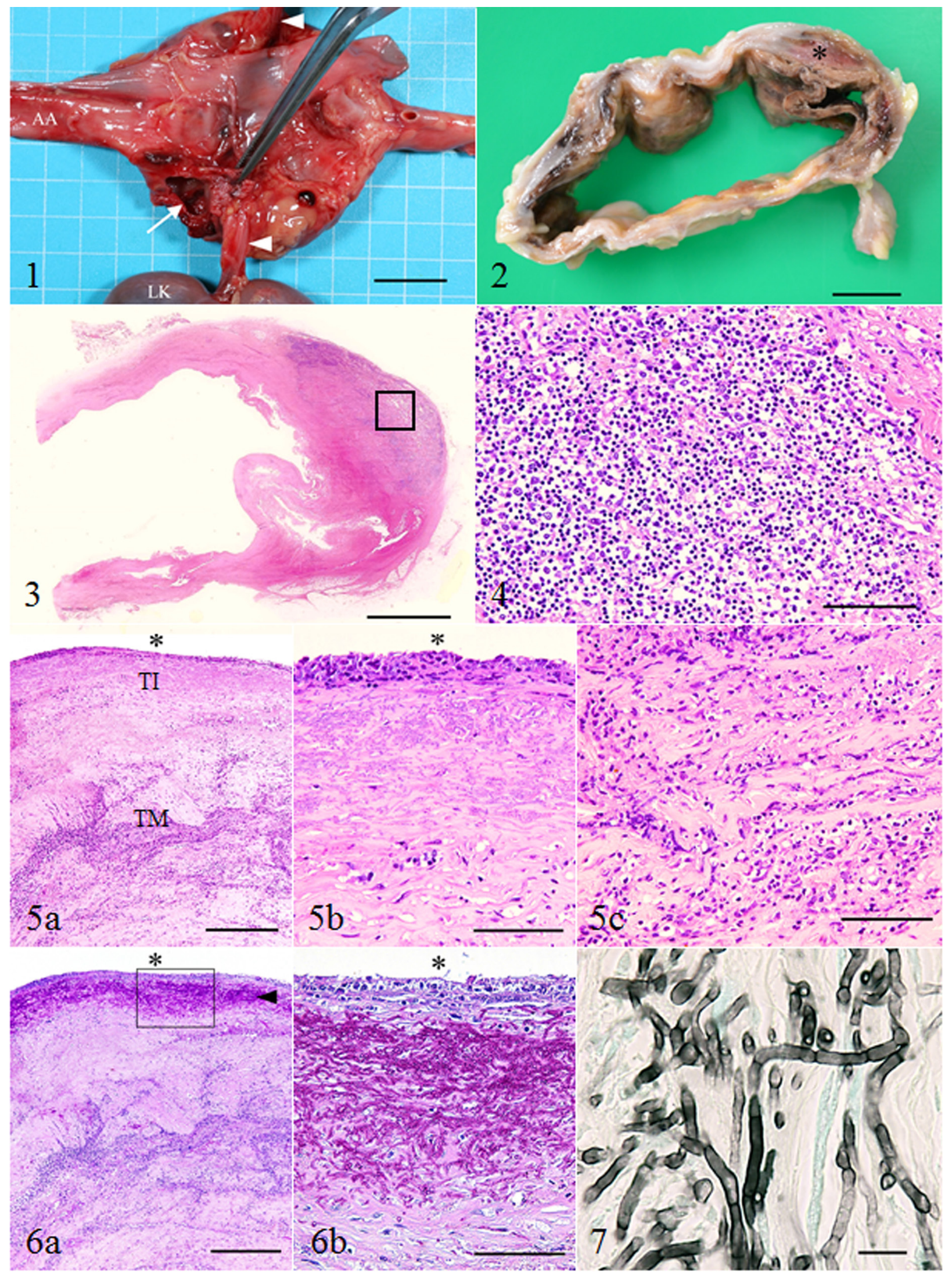


Dako) were used as primary antibodies. The sections were pre-treated with $0.1 \%$ actinase at $37^{\circ} \mathrm{C}$ for $20 \mathrm{~min}$. Primary antibodies were applied at room temperature for $60 \mathrm{~min}$. The sections were counterstained with hematoxylin. Bovine or human tissues infected with Aspergillus spp. or Zygomycetes were used as positive controls. The results of IHC revealed that intralesional fungal organisms were negative for each primary antibody.

Total DNA was extracted from the formalin-fixed paraffin-embedded tissue of the aneurysm. The tissue was mechanically lysed using ceramic beads, and DNA was extracted using a DEXPAT kit (Takara Bio INC., Otsu, Japan). The internal transcribed spacer (ITS) region, including 5.8S of ribosomal RNA gene (5.8S-ITS2 rDNA), was amplified by PCR with a primer set of ITS3 and ITS4 [19]. The PCR product was directly sequenced using a DNA sequencing kit (BigDye Terminator v3.1 Cycle Sequencing Kit, Applied Biosystems, Tokyo, Japan) and a sequencer $(3,130 \times 1$ Genetic Analyzer, Applied Biosystems). A homology search for the sequences was conducted using the BLAST of the National Center for Biotechnology Information (NCBI, Bethesda, MD, U.S.A.), and a 100\% homology was obtained by partial sequencing of 5.8S-ITS2 rRNA gene of Graphium penicillioides (Accession No. FJ914670.1) and G. basitruncatum (Accession No. HQ857746.1). The present sequence was submitted to the DNA Data Bank of Japan with the accession number LC007972. The morphology of the fungus was in conformity with that of Graphium species as previously reported, namely hyphae which were broad, septate and thin-walled with a focal bulbous dilation [8]. Based on the results of the histopathological examination and homology search, the fungus was identified as Graphium species.

From the above-mentioned findings, a diagnosis of mycotic aneurysm of the abdominal aorta was made. Mycotic aneurysms are etiologically divided into two major types: 1) infected aneurysms and 2) infections of a preexisting aneurysm. Infected aneurysms are further classified into four subtypes based on the route of infection $[1,5]$. The first type is derived from infectious endocarditis [16], the second one is a contiguous infection from a surrounding lesion [6, 9], the third one is a direct infection of an organism into the arterial wall [11], and the last one is a bacteremic seeding from another infection site, such as trauma [3]. Common pathogenic organisms that cause infectious aneurysm in humans are Salmonella, Staphylococcus, Streptococcus and Aspergillus species $[12,14]$. In dogs, there have been several reports of infectious aneurysm caused by a nematode, Spirocera lupi $[17,18]$. In addition, there was another case report on mycotic aneurysm in a dog caused by an unidentified fungus [4]. In this case, the morphology of the fungus was consistent with that of Candida species. In the present case, the aneurysm was located at the abdominal aorta, and fungal infection was confined to the vascular intima. Therefore, the fungal infection may have occurred as a result of hematogenous dissemination from another infection site. Fungal organisms might enter the bloodstream via the injured integument, as well as the respiratory system or digestive system. However, no significant lesions were observed in such systems by gross or histological examination. The dog had been neutered in the past; thus, the surgical incision might be a possible site of infection. We suspected that the dog was latently infected with Graphium species through an accident in the past, which caused the mycotic aneurysm after the primary infection site had been healed.

Graphium species belong to the Ascomycota, which are found in soil or plants. Many species included in the genus Graphium are known as plant pathogens [15]. However, there have been two human cases and one dog case of infection with Graphium species previously reported [2, 8, 10]. In these cases, the fungal infection was systemic and was related to compromised immune system. However, in the present case, immunological abnormality was not detected.

The present dog died from a ruptured aortic aneurysm. Severe fungal infection limited to the vascular intima of the aorta was observed (Fig. 6a). The morphology of the fungus was in conformity with that of Graphium species as previously reported, namely hyphae which were broad, septate and thin-walled with a focal bulbous dilation [8]. In addition, DNA sequence analysis identified the fungi as Graphium species. To our knowledge, this is the first report of an aortic aneurysm caused by Graphium species. The restricted distribution of the fungi to the vascular intima indicates that the organism reached the site via the blood stream.

Fig. 1. Gross appearance of the abdominal aorta. A focal dilation of the aorta includes the renal arteries (arrowheads). The wall of the aneurysmal lesion is ruptured (arrow). AA, abdominal aorta; LK, left kidney. Bar, $2 \mathrm{~cm}$.

Fig. 2. Cross section of the aneurysmal lesion (formalin-fixed). The vascular wall is unevenly thickened (asterisk) with hemorrhagic areas. Bar, $1 \mathrm{~cm}$.

Fig. 3. Low magnification of the aneurysm. Necrotized and hemorrhagic areas are in the vascular wall. HE. Bar, $5 \mathrm{~mm}$.

Fig. 4. Higher magnification of the area encircled in Fig. 3. Macrophages and lymphocytes infiltrate in the tunica externa. HE. Bar, $100 \mu \mathrm{m}$.

Fig. 5. (a) The inflammatory cells infiltrate mildly in the tunica intima and severely in the tunica media. (b) The vascular endothelium is detached, and the tunica intima is necrotized. (c) The fibrosis observed in the tunica media. Figures (b) and (c) are higher magnification of the tunica intima and media. TI, tunica intima; TM, tunica media; asterisk, vascular lumen. HE. Bars, $400 \mu \mathrm{m}$ (a) and $100 \mu \mathrm{m}$ (b), (c).

Fig. 6. (a) The serial section of Fig. 5a. Abundant fungal organisms are confined to the vascular intima (arrowhead). (b) Higher magnification of the area encircled in (a). Fungal organisms are observed in the inflammatory and necrotizing lesion. Asterisk, vascular lumen. PAS. Bars, 400 $\mu \mathrm{m}$ (a) and $100 \mu \mathrm{m}$ (b).

Fig. 7. The hyphae of the fungal organisms are septate with slightly uneven widths $(2-4 \mu \mathrm{m})$, irregularly branching and thin walled with bulbous dilation. GMS. Bar, $10 \mu \mathrm{m}$. 


\section{REFERENCES}

1. AbdelAzim, T. A. 2005. Infected aortic aneurysms. Acta Chir. Belg. 105: 482-486. [Medline]

2. El Feghaly, R. E., Sutton, D. A., Thompson, E. H., Fu, J., Wickes, B. L., Al-Zubeidi, D., Storch, G. A. and Burnham, C. A. 2012. Graphium basitruncatum fungemia in an immunosuppressed child post stem-cell transplantation. Med. Mycol. Case Rep. 1: 35-38. [Medline] [CrossRef]

3. Ernst, C. B., Campbell, H. C. Jr., Daugherty, M. E., Sachatello, C. R. and Griffen, W. O. Jr. 1977. Incidence and significance of intra-operative bacterial cultures during abdominal aortic aneurysmectomy. Ann. Surg. 185: 626-633. [Medline] [CrossRef]

4. Gershenson, R. T., Melidone, R., Sutherland-Smith, J. and Rogers, C. L. 2011. Abdominal aortic aneurysm associated with systemic fungal infection in a German shepherd dog. J. Am. Anim. Hosp. Assoc. 47: 45-49. [Medline] [CrossRef]

5. Hsu, R. B. and Lin, F. Y. 2007. Psoas abscess in patients with an infected aortic aneurysm. J. Vasc. Surg. 46: 230-235. [Medline] [CrossRef]

6. Isselbacher, E. M. 2005. Thoracic and abdominal aortic aneurysms. Circulation 111: 816-828. [Medline] [CrossRef]

7. Johnston, K. W., Rutherford, R. B., Tilson, M. D., Shah, D. M., Hollier, L. and Stanley, J. C. 1991. Suggested standards for reporting on arterial aneurysms. Subcommittee on Reporting Standards for Arterial Aneurysms, Ad Hoc Committee on Reporting Standards, Society for Vascular Surgery and North American Chapter, International Society for Cardiovascular Surgery. $J$. Vasc. Surg. 13: 452-458. [Medline] [CrossRef]

8. Käufer, I. and Weber, A. 1977. [Graphium fructicola as a cause for a systemic mycosis in a dog]. Mykosen 20: 39-46 [in German]. [Medline]

9. Koeppel, T. A., Gahlen, J., Diehl, S., Prosst, R. L. and Dueber, C. 2004. Mycotic aneurysm of the abdominal aorta with retroperitoneal abscess: successful endovascular repair. J. Vasc. Surg. 40: 164-166. [Medline] [CrossRef]

10. Kumar, D., Sigler, L., Gibas, C. F. C., Mohan, S., Schuh, A., Medeiros, B. C., Peckham, K. and Humar, A. 2007. Graphium basitruncatum fungemia in a patient with acute leukemia. $J$. Clin. Microbiol. 45: 1644-1647. [Medline] [CrossRef]

11. McCready, R. A., Siderys, H., Pittman, J. N., Herod, G. T., Halbrook, H. G., Fehrenbacher, J. W., Beckman, D. J. and Hormuth, D. A. 1991. Septic complications after cardiac catheterization and percutaneous transluminal coronary angioplasty. J. Vasc. Surg. 14: 170-174. [Medline] [CrossRef]

12. Miller, D. V., Oderich, G. S., Aubry, M. C., Panneton, J. M. and Edwards, W. D. 2004. Surgical pathology of infected aneurysms of the descending thoracic and abdominal aorta: clinicopathologic correlations in 29 cases (1976 to 1999). Hum. Pathol. 35: 1112-1120. [Medline] [CrossRef]

13. Mitchell, R. N. 2013. Blood vessels. pp. 327-364. In: Robbins Basic Pathology, 9th ed. (Kumar, V., Abbas, A. K., Aster, J. C., Robbins, S. L. and Perkins, J. A. eds.), Elsevier/Saunders, Philadelphia.

14. Müller, B. T., Wegener, O. R., Grabitz, K., Pillny, M., Thomas, L. and Sandmann, W. 2001. Mycotic aneurysms of the thoracic and abdominal aorta and iliac arteries: experience with anatomic and extra-anatomic repair in 33 cases. J. Vasc. Surg. 33: 106-113. [Medline] [CrossRef]

15. Okada, G. 1994. Genus Graphium. J. Antibact. Antifung. Agents 22: 45-54 [in Japanese].

16. Osler, W. 1885. The gulstonian lectures, on malignant endocarditis. $B M J$ 1: 522-526. [Medline] [CrossRef]

17. Rinas, M. A., Nesnek, R., Kinsella, J. M. and DeMatteo, K. E. 2009. Fatal aortic aneurysm and rupture in a neotropical bush dog (Speothos venaticus) caused by Spirocerca lupi. Vet. Parasitol. 164: 347-349. [Medline] [CrossRef]

18. van der Merwe, L. L., Kirberger, R. M., Clift, S., Williams, M., Keller, N. and Naidoo, V. 2008. Spirocerca lupi infection in the dog: a review. Vet. J. 176: 294-309. [Medline] [CrossRef]

19. White, T. J., Bruns, S., Lee, S. and Taylor, J. 1990. Amplification and direct sequencing of fungal ribosomal RNA genes for phylogenetics. pp. 315-322. In: PCR Protocols: A Guide to Methods and Applications. (Innis, M. A., Gelfand, D. H., Sninsky, J. J. and White, T. J. eds.), Academic Press, San Diego. 